\title{
Adenocarcinoma of the ileal pouch mucosa: a new diagnostic challenge
}

\author{
Annamaria Pronio • Giovanni Battista Levi Sandri • \\ Daniela Caporilli • Mariagrazia Coluzzi • \\ Chiara Montesani
}

Accepted: 20 December 2014 / Published online: 7 January 2015

(C) Springer-Verlag Berlin Heidelberg 2015

\section{Dear editor,}

We read with interest the manuscript recently published by O'Mahoney et al. entitled "Adenocarcinoma of the ileal pouch mucosa: case report and literature review" [1]. The authors well presented a case of adenocarcinoma of ileal pouch mucosa diagnosed after 13 years of pouch creation. They reviewed literature for true pouch adenocarcinoma, and a total of 27 patients have been described around the world. Of these, $63 \%(17 / 27)$ had neoplasia in their original proctocolectomy specimen. Mean time of adenocarcinoma development was 8.9 years. Five-year survival after excision of the pouch was $70 \%$. In our experience of 112 ileal pouch anastomosis, we had one case of true pouch adenocarcinoma. A 71-year-old man was diagnosed of ulcerative colitis for 30 years; he underwent a total colectomy 26 years ago (on 1985). Patient course was complicated by chronic pouchitis medically treated. After 11 years of follow-up, primary sclerosing cholangitis diagnosis was done. During annual endoscopic control, a polypectomy was performed. At pathology, a wide area of high-grade dysplasia with a minute focus of adenocarcinoma polyp was observed. A magnetic resonance imaging was performed, and a mucosal thickening was observed. Considering oncological indication to remove the pouch, patient age, and technical difficulty to restore intestinal continuity, the patient underwent ileal pouch excision with end ileostomy. After 34 months of follow-up, the patient is alive with no local or systemic recurrence. In our experience, mean age at surgery was 37 years old with a mean follow-up of 123 months. For a 6-month endoscopical follow-up for the first 4 years after surgery and if no complication is observed, a 12-month control is performed. We agree with O'Mahoney et al. highlighting the need for long-term follow-up and attention to these patients. Through the absence of consensus in the surveillance of pouch, many authors may suggest there own clinical practice [2-4]. However, we suggest to perform a closed follow-up with random biopsy in all patients, with or without previous neoplasia. In patients with ileal pouch anastomosis, no limits of time should be considered to be out of risk.

\section{References}

1. O'Mahoney PR, Scherl EJ, Lee SW, Milsom JW (2014) Adenocarcinoma of the ileal pouch mucosa: case report and literature review. Int J Colorectal Dis

2. Boostrom SY, Mathis KL, Pendlimari R, Cima RR, Larson DW, Dozois EJ (2013) Risk of neoplastic change in ileal pouches in familial adenomatous polyposis. J Gastrointest Surg 17(10):1804-1808. doi: 10.1007/s11605-013-2319-x

3. Herline AJ, Meisinger LL, Rusin LC, Roberts PL, Murray JJ, Coller JA, Marcello PW, Schoetz DJ (2003) Is routine pouch surveillance for dysplasia indicated for ileoanal pouches? Dis Colon Rectum 46(2): 156-159

4. Liu ZX, Xiao MB, Wu XR, Queener E, Ni RZ, Shen B (2014) Chronic pouchitis is associated with pouch polyp formation in patients with underlying ulcerative colitis. J Crohn's Colitis 8(5):363-369. doi:10. 1016/j.crohns.2013.09.020

\footnotetext{
A. Pronio • G. B. Levi Sandri $(\bowtie) \cdot$ D. Caporilli • M. Coluzzi •

C. Montesani

Department of General and Endocrine Surgery, Umberto I Policlinic

of Rome, Sapienza University of Rome, Viale del Policlinico 155,

00161 Rome, Italy

e-mail: gblevisandri@gmail.com
} 